\title{
Pagando pelos Serviços Ambientais: Uma proposta para a Reserva Extrativista Chico Mendes
}

\author{
Raimundo Claudio Gomes MACIEL ${ }^{1}$, Bastiaan P. REYDON², Jeísa Accioly da COSTA³, \\ Gardênia de Oliveira de Oliveira SALES ${ }^{4}$
}

RESUMO

Sabe-se que o processo de ocupação econômica, pós-1970, foi extremamente prejudicial ao meio ambiente e às populaçóes tradicionais da regiáo Amazônica, persistindo ainda hoje as imensas dificuldades de reprodução das famílias no interior da floresta. Um dos principais desafios na busca de um Desenvolvimento Sustentável é a viabilização do desempenho econômico das unidades produtivas, a partir dos produtos florestais não madeireiros (PFNM), e, conseqüentemente, da reprodução social dessa população. Objetiva-se no presente estudo propor uma alternativa factível de pagamento pelos serviços ambientais (PSA) promovidos pelas comunidades extrativistas, há mais de um século. Para tanto, busca-se, inicialmente, realizar uma avaliação sócio-econômica da produção familiar rural na RESEX Chico Mendes, em Xapuri-AC, no sentido de oferecer uma proposta coerente com as necessidades das famílias estudadas. Utiliza-se para tanto metodologia própria e específica, por intermédios de medidas e indicadores de resultado socioeconômico, avaliando a evoluçáo do desempenho econômico dos últimos nove anos na região. Os resultados indicam a diminuição da geração de renda de produtos oriundos do extrativismo, demonstrando as dificuldades de reprodução desse sistema e das famílias, além de realçar o fortalecimento de atividades predadoras da floresta, como é o caso da pecuária extensiva, realizada ainda de maneira rudimentar. Face aos níveis de reprodução familiar, calcula-se que o valor mínimo necessário para o PSA seria em torno US\$13/ha, evidenciando um valor necessário e, ao mesmo tempo, mais adequado frente às proposiçóes da literatura corrente, que estima valores para os mesmos serviços em torno de US\$ 50/ha.

PALAVRaS-ChaveS: Reserva Extrativista (RESEX), Desenvolvimento Sustentável, Produção Familiar Rural, Pagamento por Serviços Ambientais (PSA).

\section{Paying for Environmental Services: A proposal for the Chico Mendes Extractivist Reserve}

\begin{abstract}
It is known that the process of economical occupation, in the last forty years, it was extremely harmful to the environment and the traditional populations of the Amazon region, still persisting today the immense difficulties of reproduction of the families inside the forest. One of the principal challenges in the search of a Sustainable Development is the promotion of the economical development of the productive units, starting from the non timber forest products (NTFP), and, consequently, of the social reproduction of that population. It is aimed at in the present study to propose a feasible alternative of payment for the environmental services (PSA) promoted by the communities extrativistas, there is more than one century. For so much, it is looked for, initially, to accomplish a socioeconomic evaluation of the rural family production in Extractive Reserve (RESEX) Chico Mendes, in Xapuri-AC, in the sense of offering a coherent proposal with the needs of the studied families. It is used for so much own and specific methodology, for intermissions of measures and indicators of resulted economical, evaluating the evolution of the economical development of the last nine years in the area. The results indicate the decrease of the generation of income of products originating from of the NTFPs, demonstrating the difficulties of reproduction of that system and of the families, besides enhancing the invigoration of activities predatory of the forest, as it is the case of the extensive livestock, still accomplished in a rudimentary way. In the face of the levels of family reproduction, is calculated that the necessary minimum value for PSA would be US\$13/ha, evidencing a necessary value and, at the same time, more appropriate front to the propositions of the average literature, that esteems values for the same services around US\$ 50/ha.
\end{abstract}

KEYWORDS: Extractives Reserves (RESEX), Sustainable Development, Rural Family Production, Payment for the Environmental Services (PSA).

\footnotetext{
${ }^{1}$ Universidade Federal do Acre - UFAC, E-mail: rcgmaciel@bol.com.br

2 Universidade Estadual de Campinas - UNICAMP, E-mail: basrey@eco.unicamp.br

${ }^{3}$ Universidade Estadual de Campinas - UNICAMP, E-mail: jeisa.accioly@hotmail.com

${ }^{4}$ Universidade Federal do Acre - UFAC, E-mail: gardenia.sales@ac.gov.br
} 


\section{INTRODUÇÃO}

A extração de borracha na floresta Amazônica foi uma atividade da maior importância ao longo de várias décadas desde o início do século XX. Mas a partir dos anos 50, em funçáo do crescimento da concorrência da borracha sintética e da produzida através do sistema de plantation, principalmente na Ásia a sua obtenção através do sistema de extração tradicional na floresta entrou em uma crise profunda.

O Estado brasileiro para contrarrestar esta tendência implementou várias estratégias de desenvolvimento para a Amazônia. Um exemplo foi a "Operação Amazônia", criada a partir de 1966, com o objetivo de criar pólos de desenvolvimento e grupos de populaçóes estáveis e autosuficientes com estímulos à migração, acompanhados de incentivos ao capital privado, de melhoria da infra-estrutura e da identificação do potencial dos recursos naturais.

Com a crise nos seringais da Amazônia, especialmente na segunda metade do século XX, muitas áreas foram vendidas a fazendeiros sulistas, particularmente aos "paulistas", que começaram a transformar a floresta em pastagens, destruindo o meio de sobrevivência dos extrativistas. Muitos foram expulsos das colocaçôes ${ }^{1}$ e se viram obrigados a migrarem para a periferia urbana, passando a viver em condiçôes precárias, sem perspectiva, principalmente por se tratar de um contingente de trabalhadores sem qualificação para o típico trabalho urbano. A experiência que possuíam era o árduo trabalho braçal, outros, no entanto, permaneceram nos seringais, mantendo-se resistentes a tais mudanças.

Nesse sentido, o líder Chico Mendes defendia a criação de Reservas Extrativistas (RESEX), na qual estaria assegurada ao extrativista a posse da terra e a continuidade de suas atividades produtivas tradicionais. Segundo ele, através do adequado uso dos recursos naturais, as RESEX seriam economicamente viáveis, viabilizando a exploração de outros produtos florestais além da borracha (Hevea brasiliense) (Batista, 1995).

Ademais, o conceito de RESEX conforma-se com o conceito de Desenvolvimento Sustentável, uma vez que há uma constante busca por alternativas para superar as contradiçôes entre o crescimento econômico e a preservação ambiental. Vale notar que a sustentabilidade provém da eficiência econômica, justiça social e prudência ecológica e implica uma relação harmoniosa entre o ser humano e o meio ambiente, garantindo os benefícios do continuo uso dos recursos naturais na atualidade e no futuro. ${ }^{2}$

Dentre as principais questóes que a proposta das RESEXs se ocupou foram a desconcentração do uso da terra, a promoçáo do uso dos recursos naturais de forma prudente e da conservação da biodiversidade no território amazônico (Allegretti, 1989; Costa Filho, 1995).

Nas palavras de Cavalcanti (2002, p. 7):
As politicas públicas voltadas para o desenvolvimento da Amazônia não podem mais ignorar o desafio ambiental, expresso no aproveitamento das riquezas naturais baseado nos princípios da sustentabilidade. (...) assim a criação das Reservas Extrativistas assume a relevância como proposta dos seringueiros acreanos, visando a conservação ambiental do espaço amazônico, definindo uma forma de uso da terra e regulação fundiária.

Lado a lado estiveram quem visualizasse a implantação e maturação da RESEX como estratégia apta a promover o desenvolvimento social, econômico e ambiental da Amazônia e quem a considerasse insuficiente para tanto. Neste grupo cita-se UICN (1995) para quem,

As Reservas Extrativistas não são a panacéia para os problemas da Amazônia, nem a solução mágica para a sua ocupação, mesmo porque mais da metade da área já foi ocupada e colonizada através de diferentes projetos, especialmente agropecuários. Da superficie total, talvez apenas 20\% apresente condiçôes exigidas por lei para a implantação daquelas. Exatamente porque estâo chegando já um pouco tarde, é preciso acelerar o processo, para proteger as áreas que ainda podem ser protegidas (p. 2).

Ao avaliar a eficiência econômica do produto ícone amazônico, a borracha (Hevea brasiliense), Maciel e Reydon (2003) expóem que a atividade produtiva é tecnologicamente atrasada e se apresenta com desempenho econômico inferior ao de outras atividades, sendo necessário seu aperfeiçoamento tecnológico sob pena de tornar-se inviável, confirmando teses contrárias ao desenvolvimento amazônico ancorado no extrativismo, a exemplo de autores como Homma (1993).

Entretanto, para Maciel (2003), é possível modernizar as atividades extrativistas, tornando-as sustentáveis. As Reservas Extrativistas são justamente inovaçôes institucionais importantes para a viabilização de alternativas produtivas no seio da floresta, contribuindo, portanto, para o desenvolvimento sustentável da Amazônia, em particular na regiáo acreana.

Assim, as dificuldades econômicas por que passam os produtores extrativistas hoje estäo estreitamente relacionadas com a herança tecnológica do periodo da economia do aviamento. Alguns gargalos para mudança tecnológica são amplamente conhecidos, como a dificuldade de racionalização da produção mediante plantios racionais, mas a história econômica do setor mostra que esses gargalos estão relacionados a constrangimentos não somente devido a fatores econômicos, mas também por fatores politicoinstitucionais, além dos ecológicos (Maciel e Reydon, 2003, p. 8)

1 Unidade de Produção Familiar (UPF) do extrativista.

2 Ver: Sachs (1986), CMMAD (1991), Cavalcanti (2002) e Maciel (2007). 
Os referidos autores afirmam que, na busca de soluçóes inovadoras para superar as desvantagens competitivas, os seringueiros necessitam do apoio interativo de fatores políticos, institucionais e sociais, uma vez que para inovar é necessário, prioritariamente, de acesso às bases do conhecimento científico, cada vez mais essencial ao progresso tecnológico.

Rêgo (1999) afirma que para viabilizar o modelo de desenvolvimento sustentável para a Amazônia faz-se necessárias novas políticas públicas, com base na cultura própria das populaçóes extrativistas e em adequados sistemas de produçôes familiares, harmonizando benefícios econômicos, sociais e ambientais, conformado no que denominou de neoextrativismo.

Na ótica de Fearnside (2008), a economia da Amazônia brasileira seria quase inteiramente baseada na destruição da floresta, por intermédio da exploração predatória da madeira ou pelo desflorestamento para pastagem de gado bovino e, em algumas áreas, pela soja. Continua afirmando que as atividades sustentáveis tradicionais, tais como, o extrativismo da borracha (Hevea brasiliense) e castanha-do-Brasil (Bertholetia excelsa) existem, mas sua importância relativa é mínima do ponto de vista dos fluxos financeiros da economia atual. Ademais, o retorno financeiro sob a qual esses usos podem produzir produtos sustentáveis é limitado e freqüentemente desfavorável em relação aos usos predatórios, uma vez que o valor dos serviços ambientais não é incorporado aos fluxos de renda oriundos do extrativismo vegetal tradicional.

A viabilização da RESEX passa invariavelmente por estratégias que coordenem açóes voltadas para a viabilização econômica de atividades produtivas bem como na interaçấo positiva destas atividades, respeitando a capacidade de suporte do meio natural que a sustenta.

Assim, devem-se identificar as condiçóes econômicas mínimas dos extrativistas ali empossados que correspondam a um uso prudente dos recursos. Se, por um lado, o extrativista é contido no ímpeto de avançar desordenamente sobre os recursos existentes por já ter suprido suas necessidades básicas viabilizadas pelo mercado, por outro lado, se protege a perspectiva dos benefícios da existência dos recursos naturais na atualidade e no futuro.

Sendo assim, o presente estudo propóe uma alternativa factível de pagamento pelos serviços ambientais (PSA) promovidos pelas comunidades extrativistas, há mais de um século. Para tanto, busca-se, inicialmente, realizar uma avaliação sócio-econômica da produção familiar rural na RESEX Chico Mendes, em Xapuri-AC, no sentido de oferecer uma proposta coerente com as necessidades das famílias estudadas.

Um tema extremamente atual e instigante em torno do debate sobre o desenvolvimento sustentavel na Amazônia refere-se ao PSA, instrumento que remunera ou recompensa os produtores protetores das florestas. É uma forma de estimular a conservação, atribuída à exploração sustentável de florestas, contribuindo na reproduçấo social das populaçóes tradicionais, via distribuiçáo mais equitativa de renda.

Para Negret (2007), tratando-se de famílias que vivem em condiçôes de subsistência na RESEX, apresentando sérias dificuldades para produção e comercialização dos PFNM, a iniciativa de compensar os serviços ambientais - prestados gratuitamente pelas famílias produtoras rurais, em virtude da conservação e preservação da floresta - se justifica em termos social e ambiental, melhorando a qualidade de vida.

Destaca-se que

(...) os mecanismos de compensaçôes e prêmios pela conservação e restauração de serviços ambientais podem ser importantes instrumentos para a promoção da sustentabilidade social, ambiental e econômica, sobretudo de populaçôes rurais que habitam áreas estratégicas para a conservação da biodiversidade, a produção de água, a proteção de manaciais e florestas, a produção de alimentos sadios (...). (Born e Talocchi, 2002, apud Gusmão, 2003).

Segundo Gusmão (2003), tem-se o pagamento por serviços ambientais como um forte instrumento na consecuçáo do desenvolvimento sustentável, extensivo ao âmbito global, culminando na inclusão e melhoria do bem-estar dos produtores florestais.

No âmbito nacional existem alguns mecanismos de compensação por serviços ambientais, como, por exemplo, a Lei Chico Mendes (Lei Estadual n ${ }^{\circ} 1.277 / 99$ ) em vigor no Estado do Acre, que paga aos produtores de borracha um subsídio pelos serviços ambientais prestados no valor de $\mathrm{R} \$$ 0,70 (setenta centavos) por quilo de borracha comercializada.

No Estado do Amazonas criou-se a Bolsa Floresta, um benefício pago mensalmente às famílias que vivem nas Unidades de Conservação do Estado como uma forma de incentivar os produtores a protegerem os recursos florestais objetivando a reduçáo de práticas predatórias ao meio ambiente ${ }^{3}$.

No âmbito internacional, a Costa Rica é um país que tem se destacado na proteçáo ao meio ambiente e aos recursos naturais, adotando um mecanismo de gestáo inovador em que remunera em US\$ 64,00 o hectare protegido

A Costa Rica reconhece os seguintes serviços ambientais: diminuição de emissão de gases poluentes; proteçấo da água para uso urbano, rural ou hidrelétrico; proteção da biodiversidade para sua conservação e uso sustentado, científico e farmacêutico, de investigação e melhoramento

${ }^{3}$ Ver Agência Brasil (2007) 
genético; a proteção de ecossistemas e de formas de vida; também a beleza natural para fins turísticos e científicos.

Por outro lado, vários trabalhos buscam estimar os valores adequados para a valoraçâo dos recursos ambientais a exemplo de Pearce e Pearce (2001) que revisam ampla bibliografia referente ao tema, classificando os serviços florestais nas categorias de florestas tropicais e florestas temperadas, indicando valores que podem servir como referência para remuneraçấo dos diversos tipos de serviços ambientais. Por exemplo, os autores estimam o valor de US\$ 50,00/ha/ano para os produtos florestais não madeireiros, indicando uma importante referência para a definição de valores concernentes ao pagamento pela manutenção dos serviços ambientais na regiấo amazônica.

Desta forma, implantar um programa de remuneração para os serviços ambientais prestados por aqueles que resguardam os cada vez mais restritos fatores ambientais essenciais ao equilíbrio do meio natural é uma estratégia válida que pode propiciar uma "válvula de escape" às intervençôes humanas sobre o meio natural, especialmente na floresta amazônica, podendo auxiliar nas discussóes sobre um efetivo desenvolvimento sustentável.

\section{METODOLOGIA}

O objeto do presente estudo é a Reserva Chico Mendes, criada em 1990, com uma área de aproximadamente 970.570 ha (hectare), abrange os municípios de Assis Brasil, Brasiléia, Capixaba, Epitaciolândia, Rio Branco, Xapuri e Sena Madureira, no Estado do Acre, Brasil com uma população em torno de 1500 famílias. As Unidades de Produção Familiar (UPF) pesquisadas são denominadas colocaçóes e têm em média uma área de 300 ha. A mão-de-obra é basicamente familiar.

Para fazer a avaliação sócio-econômica da produção familiar rural na RESEX Chico Mendes trabalha-se com uma metodologia adequada e específica a este tipo de produção, que está sendo consolidada nos últimos nove anos pelo projeto de pesquisa Análise Econômica de Sistemas de Produção Familiar Rural no Estado do Acre, denominado ASPF, desenvolvido pelo Departamento de Economia da UFAC, desde 19964 . Destaca-se que o presente trabalho faz parte do referido projeto.

Assim, para a consecuçáo dos objetivos da pesquisa, buscou-se trabalhar a metodologia a partir de indicadores e índices sócio-econômicos que, por um lado, levem em consideração as peculiaridades da regiáo de estudo e, por outro, sirvam como parâmetros para relacionar as diversas regiôes e determinadas formas de organização produtiva dos produtos comercializados, comparando-as entre si e indicando as prioridades de atuaçáo para um efetivo desenvolvimento sócio-econômico sustentável. Portanto, segue uma descrição sucinta da metodologia de pesquisa.

O levantamento dos dados realizou-se por amostragem seguindo o critério de que a residência do produtor na colocação seja superior a dois anos.

A amostra é definida a partir de três etapas:

1. Estratificação da área de acordo com nível de desenvolvimento (alto, médio ou baixo), tendo como referência os critérios relativos aos volumes de produção, facilidade e qualidade de acesso, disponibilidade de infra-estrutura e assistência técnica, além do grau de organização comunitária;

2. Sorteio de metade dos conglomerados das áreas de estudo - ramais, no caso de áreas agrícolas, e, os seringais, no caso de áreas extrativistas -, tendo em vista a representatividade dentro de cada estrato definido;

3. Por fim, dentro de cada conglomerado sorteado, foi realizada uma amostragem aleatória simples, sorteandose $10 \%$ das unidades de produção, que seriam o objeto de estudo.

Utiliza-se como referência para o levantamento das informaçóes, o calendário agrícola da região, definido conjuntamente com as próprias comunidades estudadas, que compreende o período de maio do ano referência a abril do ano seguinte, que engloba o conjunto de atividades econômicas produtivas das famílias. Na presente avaliação considerou-se os anos agrícolas de 1996/1997 e 2005/2006.

Trabalha-se com medidas de resultado econômico, que são indicadores/índices que, dados os custos de produção, permitem medir o desempenho econômico do sistema de produção. Desempenho econômico é a diferença entre os valores de saída e os de entrada, as diversas relaçóes entre valores de saída e de entrada e as flutuaçôes dos valores de saída do sistema de produção.

Os principais indicadores econômicos são sucintamente descritos a seguir:

1) Resultado Bruto

Renda Bruta (RB) - indicador de escala de produção

2) Resultados Líquidos

Renda Líquida (RL) - excedente apropriado

Lucro da Exploração (LE) - possibilidade de acumulaçáo

Margem Bruta Familiar (MBF) - valor monetário disponível para a família

Nível de Vida (NV) - indicador monetário do padráo de vida

3) Medidas de Relação

${ }^{4}$ Ver http://www.ufac.br/projetos/aspf/index.htm 
Índice de Eficiência Econômica (IEE) - indicador de benefício/custo

$\mathrm{MBF} / \mathrm{Qh} / \mathrm{d}$ - índice de remuneração da mão de obra familiar

Termo de Intercâmbio (TI) - índice de apropriação da RB pelo mercado.

\section{4) Linha de Dependência do Mercado}

A produção familiar rural depende parcialmente do mercado para a aquisiçáo de produtos ou bens e serviços necessários à sua manutençáo, especialmente biológica, pois parte de suas necessidades de consumo são satisfeitas com o autoconsumo e o restante é comprado no mercado.

Assim, define-se como linha de dependência do mercado os valores medianos gastos com o consumo no mercado, adicionado das compras relacionadas à reposição do capital fixo (máquinas, equipamentos, ferramentas, benfeitorias etc.) disponível para a manutenção dos meios de produção existentes.

\section{5) Avaliação estratégica ${ }^{5}$}

Trabalha-se com alguns indicadores que buscam avaliar disponibilidade e o desempenho de ativos, capacitaçóes e estratégias competitivas.

\section{RESULTADOS E DISCUSSÕES}

\section{RESULTADOS SOCIOECONÔMICOS DA RESERVA EXTRATIVISTA CHICO MENDES}

De acordo com a tabela 1 , foi observado que atualmente os produtos extrativistas, em termos relativos, perderam um pouco de sua importância como principal gerador de renda bruta para as famílias extrativistas, visto que, no período 1996/1997, os produtos extrativistas geravam quase metade da renda bruta para as famílias em estudo, destacando-se a borracha e a castanha, como principais produtos do sistema.

Todavia, no período de 2005/2006, nota-se uma abrupta queda de rendimento dos produtos extrativistas, especialmente a proveniente da produção de borracha - responsável por apenas 9,57\% da renda gerada na RESEX Chico Mendes, denotando as dificuldades de produçáo desse produto.

Assim, destaca-se, por um lado, que o PSA incorporado ao preço da borracha na regiáo foi insuficiente para estimular os extrativistas da regiáo, visto que o custo unitário de produção, calculado para o período em questáo, era superior ao preço praticado. Por outro lado, pode-se inferir que essa parcela de quase $10 \%$ de renda bruta gerada decorre justamente do incentivo proporcionado pelo PSA, já que sem esse estímulo a produçáo de borracha seria provavelmente nula.

\footnotetext{
${ }^{5}$ Ver Maciel (2007), Aaker (1989) e Chandler e Hanks (1994)
}

Contudo, o extrativismo vegetal continua sendo a principal atividade na RESEX Chico Mendes. Isto pode ser creditado à produçáo de castanha-do-Brasil.

Conforme a tabela 1 , a queda da renda oriunda dos produtos extrativos não foi pior devido aos rendimentos procedentes da produção e comercializaçáo de castanha-doBrasil, que nos últimos sete anos têm sofrido ampla valorização no mercado nacional e internacional. Além disso, as boas práticas introduzidas no seu processo produtivo levaram à sua certificaçâo e, conseqüentemente, a novos nichos de mercado com melhores preços, o que indica uma alternativa para os produtos extrativistas.

No período 2005/2006 observa-se que no processo de diversificação produtiva realizado pelas famílias da RESEX Chico Mendes, os produtos oriundos das criaçôes sofreram uma elevaçấo com $30,37 \%$ da renda bruta no sistema produtivo, com destaque para a criaçáo de gado bovino, que, em nove anos, tem uma escalada de $13,34 \%$ para $17,59 \%$ da renda gerada entre as famílias da RESEX Chico Mendes.

Todavia, o que mais impressiona é o aumento da produção de gado bovino em termos físicos, pois, na evolução do período considerado, houve um incremento na produção de cabeças de gado (bezerros, novilhas, garrotes, vacas e boi de corte) em torno de $300 \%$, principalmente na produção de bezerros.

Do ponto de vista ambiental, isto é preocupante, uma vez que a produção de gado bovino é completamente extensiva e isso significa, obviamente, que se necessita de maior extensão de pasto e, conseqüentemente, maiores níveis de

Tabela 1 - Evolução da Renda Bruta na Resex Chico. Mendes, Acre 1996/1997-2005/2006.

\begin{tabular}{lcc}
\hline \multirow{2}{*}{ Descrição } & \multicolumn{2}{c}{$\%$ Renda Bruta } \\
\cline { 2 - 3 } & $1996 / 1997$ & $2005 / 2006$ \\
\hline Extrativismo & $48,04 \%$ & $45,34 \%$ \\
\hline Castanha & $25,18 \%$ & $27,30 \%$ \\
\hline Borracha & $22,86 \%$ & $9,57 \%$ \\
\hline Castanha Certificada & $0,00 \%$ & $3,69 \%$ \\
\hline Agricultura & $22,56 \%$ & $24,28 \%$ \\
\hline Feijão & $5,09 \%$ & $1,79 \%$ \\
\hline Arroz & $5,94 \%$ & $7,37 \%$ \\
\hline Macaxeira & $6,06 \%$ & $10,63 \%$ \\
\hline Outras & $5,48 \%$ & $4,50 \%$ \\
\hline Criações & $29,40 \%$ & $30,37 \%$ \\
\hline Aves & $6,55 \%$ & $5,24 \%$ \\
\hline Bois & $13,34 \%$ & $17,59 \%$ \\
\hline Porcos & $8,24 \%$ & $6,07 \%$ \\
\hline Outras & $1,26 \%$ & $1,48 \%$ \\
\hline
\end{tabular}

Fonte: Banco de dados ASPF 
desflorestamento - NO INTERIOR DA RESEX! E o que é pior nessa constatação é verificar que esse processo não se traduz em maiores níveis de renda.

Segundo a tabela 2 , o resultado da diversificação produtiva - especialmente relacionado à atividade pecuária (ver tabela 1) - efetuado pelos extrativistas em questão indica que a renda bruta das famílias aumentou em mais de $6,92 \%$ nos últimos nove anos, tendo-se um pequeno aumento no valor monetário embolsado (MBF) por cada família no final do período.

Tabela 2 - Evolução do desempenho econômico na Resex Chico Mendes, Acre, 1996/1997-2005/2006.

\begin{tabular}{lcccc}
\hline Indicadores & Unidade & $1996 / 1997$ & $2005 / 2006$ & Variação \\
\hline Renda Bruta & $\mathrm{R} \$ /$ mês & 318,00 & 340,00 & $6,92 \%$ \\
Renda Líquida & $\mathrm{R} \$ /$ mês & 33,70 & 151,49 & $349,52 \%$ \\
Margem Bruta Familiar & $\mathrm{R} \$ /$ mês & 267,26 & 291,39 & $9,03 \%$ \\
\hline Autoconsumo & $\mathrm{R} \$ /$ mês & 310,81 & 268,36 & $-13,66 \%$ \\
Nível de Vida & $\mathrm{R} \$ /$ mês & 619,19 & 583,56 & $-5,75 \%$ \\
Índice de Eficiência & Und. & 0,92 & 0,59 & $-36,29 \%$ \\
Econômica & Und. & 0,69 & 1,03 & $49,91 \%$ \\
\hline Termo de Intercâmbio & & & & \\
\hline
\end{tabular}

Fonte: Banco de dados ASPF

Observa-se que a RL obtida no ano agrícola 96/97 era bem reduzida e, no período mais recente, apresenta um aumento de 349,52\%. Isso está relacionado com o tipo de produçáo explorada nas colocaçóes. Ora, tendo em vista que a principal diversificação produtiva consiste na criaçáo de gado bovino e, em menor escala, de porcos, destaca-se que essas criaçōes são manejadas nas colocaçôes de forma bastante rústica, com reduzida qualidade no tratamento das criaçóes - numa frase: o porco é criado como porco e náo como suíno.

Por outro lado, o acréscimo na renda levou as famílias daquela localidade a adquirir mais mercadorias no mercado (tabela 3) e, conseqüentemente, reduzir o autoconsumo (tabela 2). Foi notado que nos últimos nove anos o nível de vida na regiâo apresentou uma queda. Isso significa que melhor renda não significa melhor nível de vida, em termos monetários.

Vale notar que quando se troca o autoconsumo de produtos como leite, aves e outros produtos naturais por produtos industrializados reduz-se a qualidade de vida em termos de saúde. Além disso, destaca-se nessa troca uma maior dependência do mercado e, por conseguinte, na maior necessidade de gerar receita.

Essa necessidade é ratificada pela tabela 3, visto que em virtude de se ter um maior valor monetário disponível (MBF) para a família, tornando assim possível a aquisição de mais bens e serviços comprados, aumentou-se o custo fixo da unidade de produçáo, com a reposiçáo e aquisição de mais itens de capital fixo, tais como, máquinas, equipamentos, animais de trabalho, benfeitorias etc.
Um fator que proporcionou essa mudança foi a melhoria visível do acesso às localidades, proporcionando facilidade de deslocamento dos produtores até o mercado na zona urbana da cidade. Porém, isso gerou um endividamento maior do que havia anteriormente. Ao aumentar a renda passou-se a comprar mais, devido à demanda reprimida por mercadorias necessárias na reprodução da família e UPF, contudo, as compras foram além do aumento alcançado nos últimos nove anos.

As dificuldades geradas pela ineficiência econômica das unidades de produção familiar podem ser vislumbradas no gráfico 1, visto que $90 \%$ das famílias que moram no interior da RESEX Chico Mendes embolsam uma remuneração, proveniente do processo produtivo, inferior às suas necessidades de consumo essencialmente supridas pelo mercado.

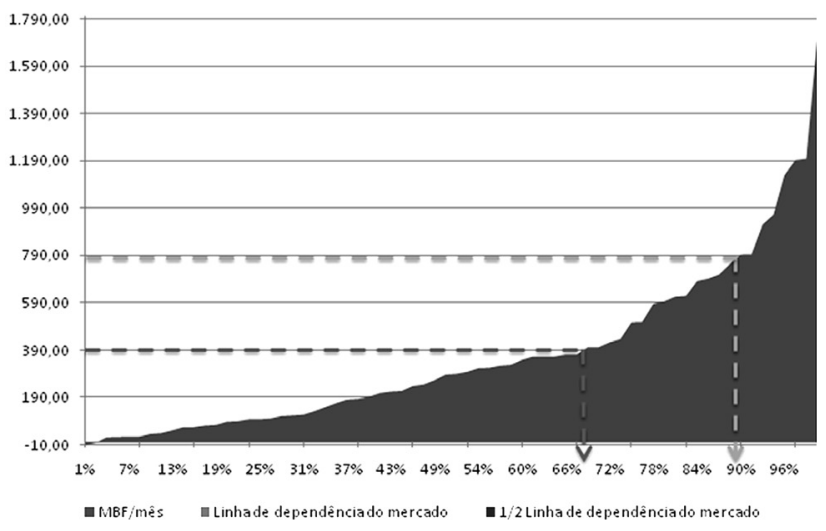

Gráfico 1 - Linha de Dependência do Mercado da Resex Chico Mendes, 2005/2006, Acre

Fonte: Banco de dados ASPF

Vale notar que cerca de $70 \%$ das famílias não conseguem suprir metade das referidas necessidades, evidenciando as dificuldades de geração e apropriação de renda no interior das RESEX, principalmente, a partir dos produtos florestais náomadeireiros. Isto demanda a busca por estratégias alternativas para compor a renda em especial do ponto de vista produtivo - notadamente no caminho de alternativas predatórias como é o caso da pecuária e da madeira.

Por outro lado, para cobrirem as dívidas as famílias se assalariam fora da UPF, além de receberem também transferências governamentais de renda. Isto é, de acordo com a tabela 3 , um terço das famílias estudadas tem membros trabalhando fora da UPF e recebem uma remuneração que vem a contribuir para a renda familiar. Ademais, $43 \%$ das colocaçóes pesquisadas têm algum membro da família que recebe algum benefício, como aposentadoria ou bolsas oferecidas pelo governo federal.

Isso demonstra que muitas famílias apresentam certo grau de dependência de assalariamento e transferências de 
Tabela 3 - Resultado do desempenho econômico na Resex Chico Mendes, Acre, 2005/2006.

\begin{tabular}{lcc}
\hline Indicadores & Unidade & $\begin{array}{c}\text { Resultados por UPF* } \\
(2005 / 2006)\end{array}$ \\
\hline Renda Bruta (RB) & $\mathrm{R} \$ / \mathrm{mês}$ & 340,00 \\
Renda Bruta Total (RBT) & $\mathrm{R} \$ / \mathrm{mês}$ & 439,17 \\
$\%$ RB na RBT & $\%$ & $77 \%$ \\
Nível de Vida & $\mathrm{R} \$ / \mathrm{mês}$ & 583,56 \\
Depende de Assalariamento & $\%$ & $25 \%$ \\
Depende de Transferências de Renda & $\%$ & $43 \%$ \\
\hline
\end{tabular}

Fonte: Banco de dados ASPF

renda, que surgiram justamente para auxiliar na manutenção das famílias de baixa renda, contudo, sem o intuito de criar dependência.

Ora, o PSA serve justamente para corrigir os preços dos PFNM e remunerar mais adequadamente os extrativistas amazônicos, liberando-os das transferências governamentais. Além disso, deve-se buscar internalizar o PSA aos preços via mercado para que não se transforme em nova dependência de recursos públicos.

Não obstante, vale ressaltar que, mesmo com as dificuldades de manutenção na floresta, não compensa para os extrativistas saírem de suas colocaçóes e se mudarem para as periferias das cidades, pois segundo a tabela 2, o nível de vida total (NV), em termos monetários, representa cerca de 1,4 salário mínimo mensais, sendo uma renda significativa em relação aos rendimentos auferidos pelas populaçóes consideradas pobres que moram nas periferias das cidades.

Ademais, foi percebido que as dificuldades encontradas pelos extrativistas residem justamente nos baixos rendimentos auferidos principalmente com a produção e comercialização de produtos florestais não-madeireiros, em especial pelos baixos preços de produtos com mercados estabelecidos, a exemplo da borracha e castanha.

Contudo, tais mercados falham em não remunerar adequadamente tais produtos em virtude dos benefícios sócioambientais que os mesmos apresentam. O mais interessante é observar, no gráfico 2, que os próprios produtores asseveram que os atributos que o tornam mais competitivos derivam das qualidades sócio-ambientais (localização, ou seja, morar na própria floresta e a reputação pela qualidade dos produtos) dos produtos florestais náo madeireiros produzidos no interior das RESEX.

Assim, pode-se afirmar que as famílias extrativistas poderiam estar em outro nível de qualidade de vida, incluindo as condiçóes ambientais em que vivem, se fossem devidamente remuneradas pela histórica proteção ambiental que exercem a mais de um século, produzindo riquezas que efetivamente são apropriadas por outros.

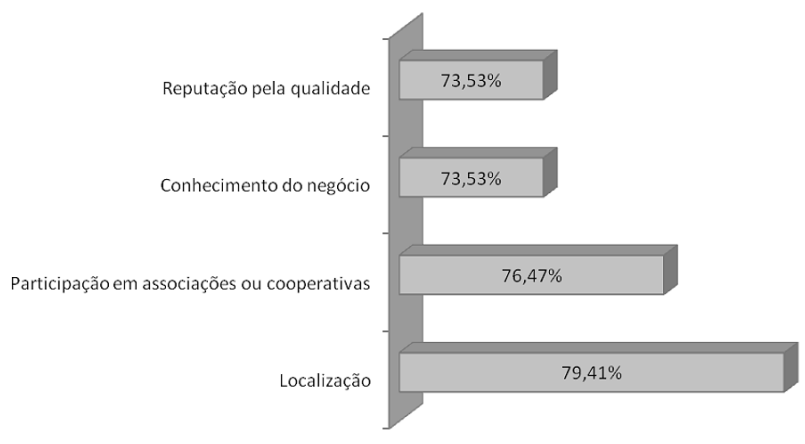

Gráfico 2 - Avaliação estratégica: disponibilidade de ativos e capacitações (vantagem) na Resex Chico Mendes, Acre, 2005/2006

Fonte: Banco de dados ASPF

Neste sentido, o pagamento pelos serviços ambientais aos extrativistas, em particular nas RESEX, se faz urgente dado os descaminhos do processo de desenvolvimento evidenciado na Amazônia, pois os serviços ecossistêmicos, bem como as populaçóes tradicionais que sempre os mantiveram, estáo seriamente ameaçados.

\section{PARA UMA PROPOSTA DE PAGAMENTO POR SERVIÇOS AMBIENTAIS - PPSA}

Diante dos resultados apresentado no tópico anterior, é proposto o pagamento pelos serviços ambientais prestados pelas famílias trabalhadoras rurais, como incentivo a prática do uso sustentável dos recursos extraídos no seio da floresta. De modo que seja viabilizada tanto a reprodução social quanto a manutençáo do ecossistema florestal, premiando os "responsáveis pela gestáo florestal" pelos serviços prestados à sociedade em geral.

Em última instância, as propostas de pagamentos pelos serviços ambientais a nível internacional definem o valor da remuneração a partir do custo de oportunidade, evidenciado na região em estudo. Entretanto, também é proposto no presente trabalho um outro olhar, em detrimento do custo de oportunidade, observando-se a manutençáo dos serviços ambientais a partir do custo social requerido para a reprodução familiar, ou seja, do mínimo necessário para viabilizar as famílias e o seu modus vivendi.

Assim, é proposto a criaçáo de um Programa de Pagamento de Serviços Ambientais (PPSA) cuja finalidade é a preservação dos recursos naturais a partir da preservação das mínimas condiçôes de manutenção e reprodução das unidades de produçáo familiar dos extrativistas.

O pagamento proposto está condicionado, por um lado, à linha de reproduçáo familiar, que representa a remuneraçáo mínima necessária para a família cobrir os custos dos bens e serviços comprados no mercado, além da reposição dos custos fixos para manter a unidade produtiva em regular operação. Por outro, condiciona-se também à receita bruta 
auferida a partir da comercialização de PFNM pré-definidos, respeitando-se o manejo e volume de produção adequada para a manutenção do ambiente.

Este mecanismo funciona como um gatilho, pois à medida que as famílias não consigam atingir, a partir de seus esforços produtivos, a renda necessária para cobrir tais necessidades, o programa de pagamento pelos serviços ambientais atua cobrindo a diferença necessária para a reprodução das famílias. Claro que esse critério é semelhante aos utilizados para a concessão de subsídios aos produtores de borracha ao longo do tempo. Entretanto, diferentemente do subsídio, buscase internalizar via preços uma apropriada remuneração dos serviços ambientais conservados pelos extrativistas amazônicos.

Os beneficiários deste programa serão as famílias extrativistas que vivem da exploraçâo dos PFNM na Reserva Extrativista Chico Mendes.

Para a regiẫo da RESEX Chico Mendes a linha de reproduçâo familiar, em termos monetários, foi medianamente calculada em torno de R \$ 9.376,00/ano/UPF.

Contudo, conforme tabela 4, considerando-se apenas as rendas oriundas dos PFNM - em virtude de que as demais atividades produtivas empreendidas nas UPF's são claramente de subsistência ou autoconsumo - as famílias receberiam, em média, $\mathrm{R} \$ 2.840,00 /$ ano, a partir da comercialização dos dois principais PFNM: borracha e castanha.

Portanto, a diferença a ser coberta pelo Programa de Pagamento de Serviços Ambientais seria de R \$ 6.536,00/ano/ UPF. Calcula-se ser necessário R \$9.804.000,00 /ano para cobrir os custos do PSA para toda a RESEX Chico Mendes.

O orçamento previsto para o PSA seria estabelecido de acordo com o desempenho de unidade de produção como um todo. Todavia, o pagamento efetivo pelos serviços prestados estaria atrelado à comercialização dos produtos representativos dos PFNM.

Nesta proposta se estabelece os produtos borracha e castanha, pois, além de ainda serem produtos representativos, são atividades desenvolvidas por mais de uma centena de anos que, em sua forma e limites tradicionais, respeitam a capacidade de suporte do meio ambiente.
Sendo assim, considerando a produção média histórica da produção de borracha, caso todo o PSA fosse pago a este produto, o extrativista, além de auferir renda da comercialização normal, ainda receberia cerca de $\mathrm{R} \$ 10,89$ / $\mathrm{kg}$ comercializado. De outro modo, caso fosse pago com base apenas na comercializaçáo de castanha-do-Brasil, a renda do produtor seria aumentada em $\mathrm{R} \$ 32,68 /$ lata. (tabela 4)

O fato é que o produtor teria um crédito de $\mathrm{R} \$$ 6.536/ano, que pode ser deduzido a partir da remuneraçáo da combinaçáo dos referidos PFNM ou de um produto especificamente. Destarte, pode-se avançar bastante na adaptação para regiôes distintas que produzem PFNM diferentes e/ou complementares à borracha e castanha, bastando apenas recalcular o PSA a ser remunerado por unidade comercializada de determinado produto representantivo.

Outro fator implícito é a noção de limites produtivos, tendo em vista que, estabelecido o valor máximo do PSA e a remuneração por unidade de produto, também se discute a questâo de volume de produção. Isto qualifica a proposta efetivamente quanto ao aspecto sócio-ambiental.

Do ponto de vista produtivo, estabelece-se que, no limite, serão remunerados serviços ambientais com base na produção média histórica do PFNM, no caso da borracha em 600 $\mathrm{kg} / \mathrm{ano} / \mathrm{UPF}$. Assim, foi respeitado os limites ambientais, desencorajando o extrativista a produzir além deste ponto, impactando positivamente no processo de regeneraçấo das espécies.

Por outro lado, do ponto de vista financeiro, em virtude da existência de um contexto propício à compensação financeira pelos serviços prestados, vale ressaltar que o estabelecimento de um valor fixo pressupóe a impossibilidade de atitudes oportunistas. Portanto, propôe-se, como pagamento de serviços ambientais, um valor mínimo necessário para satisfazer a reprodução familiar na regiáo de estudo. Ou seja, busca-se primeiro preservar as condiçóes suficientes para a manutenção do ser humano que resguardam o meio ambiente e, concomitantemente, se estaria apoiando a conservação dos recursos naturais/ambientais. Protege-se, dessa forma, o homem e o meio ambiente.

Tabela 4 - Valores propostos para o PSA na RESEX Chico Mendes, Acre, Brasil - valores em R\$.

\begin{tabular}{|c|c|c|c|c|c|c|c|c|}
\hline PFNM & Qde & Und. & Preço & $\mathrm{RB}$ & LRF & $\begin{array}{l}\text { PSA - Por } \\
\text { Produto** }\end{array}$ & PSA -Total/UPF & $\begin{array}{c}\text { PSA -RESEX Chico } \\
\text { Mendes }\end{array}$ \\
\hline UPF & - & - & - & $2.840,00$ & & & & \\
\hline Borracha & 600,00 & $\mathrm{~kg}$ & $1,40^{*}$ & 840,00 & $9.376,00$ & 10,89 & $6.536,00$ & $9.804 .000,00$ \\
\hline Castanha & 200,00 & Lata & 10,00 & $2.000,00$ & & 32,68 & & \\
\hline
\end{tabular}

Obs.: * Sem o subsídio da Lei Chico Mendes, pois a atual proposta poderia substituí-lo; ** Preço a ser pago por um único produto considerando-se o PSA; PFNM - Produtos florestais não-madeireiros; Qde - Quantidade; RB - Renda Bruta; LRF - Linha de Reprodução Familiar; PSA - Pagamento pelos Serviços Ambientais; UPF - Unidade de Produção Familiar; RESEX - Reserva Extrativista. 
Neste contexto, as criaçóes, em particular de bovinos, bem como a lavoura branca (arroz, feijão, milho e macaxeira), recorrentemente insustentáveis do ponto de vista econômico e ambiental, dado o nível tecnológico utilizado pelas famílias, serão amplamente estimuladas para a produção de autoconsumo e reserva de valor, no caso dos bovinos.

A proposta do PAS foi desenvolvida para atualizar a Lei Chico Mendes, existente no Estado do Acre-Brasil, a qual remunerava os serviços ambientais realizados por extrativistas com base em sua produção de borracha. A partir desta atualização da Lei Chico Mendes, consubstanciado no PAS, tem-se um instrumento apto a remunerar serviços ambientais tendo como referência qualquer produto florestal não-madeireiro.

A remuneração do PAS é ancorado na produção de produtos florestais náo-madeireiros, ligando-se, por um lado, a uma atividade que historicamente mostrou-se ambientalmente sustentável e tendo, por outro lado, limite de remuneração especifico por produto, desestimulando aos extrativistas ultrapassar os limites de produçáo histórica de determinado produto. Desta forma, a metodologia do PAS aqui exposta respeita a proposta de desenvolvimento sustentável, também por considerar tradiçôes e hábitos das comunidades florestais bem como os limites do ambiente considerado.

Como alternativa para financiar tal proposta foi citado o trabalho de Gusmão (2003), que elenca uma série de dispositivos legais que asseguram proteção aos recursos naturais a partir de compensaçáo financeira para quem os protege ou os utiliza moderadamente.

Exemplo de alguns destes mecanismos são as Leis $\mathrm{n}^{\circ}$ 8.510/90, do Estado de Sáo Paulo, que estabelece que 25\% do ICMS arrecadado seja distribuído entre os municípios que promovem a preservaçấo do meio ambiente. Além disso, cita a Lei Chico Mendes, que inicialmente oferecia um subsidio de $\mathrm{R} \$ 0,60$ por kg de borracha, sendo atualizado, em 2005, para $\mathrm{R} \$ 0,70 / \mathrm{kg}$.

No Estado do Amazonas o governo lançou a Bolsa Floresta, um mecanismo remunera as famílias que não desmatam a região. Cada família recebe mensalmente o valor correspondente a $\mathrm{R} \$ 50,00$ pela a conservação das florestas.

Além destes, ainda existem mecanismos potencialmente financiadores do programa que pode representar a salvaguarda das áreas florestadas em análise, por exemplo, o Fundo Nacional de Desenvolvimento Florestal (FNDF), instituído pela Lei 11.284/2006, Lei de Gestâo das Florestas Públicas, que prevê a taxação pelo uso do recurso florestal com intuito de viabilizar a manutenção das próprias florestas.

\section{CONCLUSÃO}

$\mathrm{Na}$ Amazônia, buscam-se alternativas produtivas para a promoçâo do táo propalado desenvolvimento sustentável, ou seja, alternativas economicamente eficientes, socialmente justas e ambientalmente corretas, especialmente junto às comunidades tradicionais da região, claramente excluídas das formas de ocupação econômica implementadas após os anos 1970 .

Como alternativa de desenvolvimento sustentável surgem as Reservas Extrativistas. Mas, ao longo do processo de sua implementação, as famílias que moram nessas áreas estão encontrando imensas dificuldades de manutenção e isso tem levado a diversificar suas produçóes no caminho de atividades predatórias, como, por exemplo, a criação de gado bovino, o que está representando sérios problemas quanto ao desflorestamento proveniente dessa atividade.

No presente estudo constatou-se os baixos rendimentos gerados pelos PFNM, que estão sendo substituídos pela renda da pecuária. Porém, a pecuária além de não garantir a manutenção das famílias, está providenciando o aumento do desflorestamento no seio da floresta.

Como alternativa de renda, propóe-se o pagamento pelos serviços ambientais providenciados pelos extrativistas que moram nas RESEX, em particular na Chico Mendes, vislumbrando a conservação tanto das famílias quanto do ambiente florestal.

Não obstante, a proposta visa garantir as condiçóes suficientes para a reprodução das famílias e da própria unidade produtiva, mudando o foco da valoraçáo ambiental notadamente relacionado ao custo de oportunidade para a cobertura do custo social, que, em última instância, também cobre a conservação ambiental.

Assim, destaca-se que os valores resultantes da proposta se mostram factíveis de serem implementados tendo em vista que o PSA oriundo ficou em torno de US\$13/ha (ou R \$ 22,00/ ha), bem abaixo da média proposta pela literatura e do que atualmente é praticado na Costa Rica, cerca de US\$ 50/ha.

\section{BIBLIOGRAFIA CITADA}

Aaker, D. A. 1989. Managing Assets And Skills: the key to a sustainable competitive advantage. California Management Review, v. 31, n. 2, p. 91-106, winter. Disponível em: <http:// www.periodicos.capes.gov.br>.

Allegretti, M. H. 1989. Extractive Reserves: a proposal for forest development Amazon. R. Pará Desenvolvimento, Extrativismo vegetal e reservas extrativistas, Belém, n.25, p. 3-29, jan./dez. (in Portuguese)

Batista, A. V. C. 1995. Extractive Reserves: Origin, Defence and Questioning. Monografia de graduação, UFAC, Rio Branco, Acre. (in Portuguese, with abstract in English) 
Cavalcanti, F. C. S. 2002. Environmental Policy in the Amazon: A Study on the Extractive Reserves. Tese de Doutoramento em Economia, IE/UNICAMP, Campinas, 240 p. (in Portuguese, with abstract in English)

Chandler, G. N.; Hanks, S. H. 1994. Market Attractiveness, Resource-Based Capabilities, Venture Strategies, and Venture Performance. Journal of Business Venturing, v. 9, p. 331-349. Disponível em: <http://www.periodicos.capes.gov.br>.

CMMAD. 1991. Our Common Future. Editora da Fundação Getúlio Vargas, 2. ed., Rio de Janeiro, 430 pp. (in Portuguese)

Costa Filho, O. S. 1995. Extractive Reserve - Sustainable Development and Quality of Life. Dissertação de Mestrado em Economia, UFMG, Belo Horizonte, Minas Gerais, 156 p. (in Portuguese, with abstract in English)

Fasiaben, M. C. R. et. al. 2007. Estimated contribution of funds for a System of Payment for Environmental Services in the Brazilian Amazon. In: Anais do VII Encontro da Sociedade Brasileira de Economia Ecológica, Fortaleza. (in Portuguese)

Fearnside, P. M. 2008. Amazon Forest maintenance as a source of environmental services. In: Anais da Academia Brasileira de Ciências, v. 80, $\mathrm{n}^{\circ}$ 1, Rio de Janeiro. Disponível em: <http:// biodiversidadeacreana.blogspot.com/2008/03/amazon-forestmaintenance-as-source-of.html>.

FONAFIFO - Financing National Forest Fund. 2008. Disponível. em: <http://www.fonafifo.com/paginas_espanol/servicios_ ambientales/servicios_ambientales.htm>. (in Spanish)

Gusmao, A. V. P. 2008. Global environmental problems and compensation for environmental services as an alternative for protection of social capital and ecological. Disponível em: <http:// jus2.uol.com.br/doutrina/texto.asp?id=6341 >. (in Portuguese)

Homma, A. K. O. 1993. Plant Extractivism in the Amazon: Limitations and opportunities. EMBRAPA-SPI, Brasília, 202 pp. (in Portuguese)
Maciel, R. C. G. 2003. Islands High Productivity: Innovation essential for the maintenance of rubber tappers in the Extractive Reserves. Dissertaçáo de Mestrado em Desenvolvimento Econômico, Espaço e Meio Ambiente, IE/UNICAMP, Campinas, 88 p. (In Portuguese, with abstract in English)

.; Reydon, B. P. 2003. Islands High Productivity: Innovation in the Amazon environment. In: Anais do XLI Congresso Brasileiro de Economia e Sociologia Rural, Juiz de Fora, Minas Gerais. (in Portuguese)

Mota, A. 2008. Amazon launches climate change law and announces payment of Bolsa Floresta. Disponível em: <http://www.agenciabrasil.gov.br/noticias/2007/06/05/ materia.2007-06-05.3012774626/view>. (in Portuguese)

Negret, F. 2008. Brazil - Compensation for Environmental Services to Family Farmers. Disponível em: <http://www.adital.com.br/site/ noticia.asp?lang=PT\&cod $=28063>$. (in Portuguese)

Pearce, D. W.; Pearce, C. G. T. 2001. The value of forest ecosystems. Convention on Biological Diversity. February.

Rêgo, J. F. 1999. Amazon: from extractivism to neoextractivism. Ciência Hoje, Rio de Janeiro, v. 25. n. 147, p. 62-65. (In Portuguese)

.; Costa Filho, O. S.; Braga, R. A. R. (Eds.). 2003. Economic analysis of production systems in rural family in the region of Vale do Acre - 1996/1997. UFAC/SEBRAE/The Ford Foundation, Rio Branco, Acre, $80 \mathrm{pp}$.

Sachs, I. 1986. Ecodevelopment: grow without destroying. Vértice, São Paulo. (in Portuguese)

UICN. 1995. Extractive Reserves. UICN, Gland, Suiça e Cambridge, Reino Unido. (in Portuguese)

Recebido em 11/03/2009

Aceito em 16/11/2009 